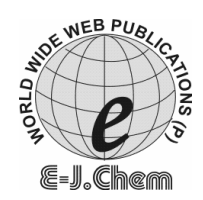

ISSN: 0973-4945; CODEN ECJHAO

E-Journal of Chemistry

http://www.e-journals.net

2009, 6(4), 1247-1252

\title{
Synthesis, Characterization and Antimicrobial Activity of Metal Chelates of 5-(4- $N, N$-Diethylamino sulfonyl phenyl azo)-8-hydorxy quinoline
}

\author{
A.U. PATEL \\ Shri M \& N. Virani Science College, \\ "Yogidham" Kalawad Road, Rajkot, Gujarat, India. \\ aup_bhoolku@yahoo.co.in \\ Received 31 December 2008; Accepted 25 February 2009

\begin{abstract}
Abstratct: 4- $N, N$-Diethylamino sulfonyl phenyl amine was synthesized by diazotization and coupled with 8-hydroxyquinoline. The resultant 5-(4- $N, N-$ diethylamino sulfonyl phenyl azo)-8-hydorxy quinoline (DSAQ) was characterized by elemental analysis and spectral studies. The transition metal chelates viz. $\mathrm{Cu}^{2+}, \mathrm{Ni}^{2+}, \mathrm{Co}^{2+}, \mathrm{Mn}^{2+}$ and $\mathrm{Zn}^{2+}$ of DSAQ were prepared and characterized by metal-ligand (M:L) ratio. IR and reflectance spectroscopy and magnetic properties. The anti fungal activity of DSAQ and its metal chelates was screened against various fungi. The results show that all these samples are good antifungal agents.
\end{abstract}

Keywords: 8-Hydroxy quinoline, Magnetic moment, Metal chelates, Antifungal properties.

\section{Introduction}

8 -Hydroxyquinoline is well known as an analytical reagent ${ }^{1,2}$. It's various derivatives ${ }^{3}$ are also useful in pharmaceuticals. Several azo dyes based on 8-quinolinol (8-HQ) are also reported for dyeing of textiles as well as their chelating properties. Various derivatives based on quinolinol have also been reported for their chelating property. The literature survey reveals that the azo dyes based on sulfonylmide of 8-HQ have not been reported so far. Hence considering the research gap, present paper deals with synthesis, characterization and chelating properties of 5-(4- $N, N$-diethylamino sulfonyl phenylazo)-8-hydroxy quinoline (DSAQ). The research work is shown in Scheme 1.

\section{Experimental}

4-(N-N-Diethylamino sulfonyl) aniline was prepared according to the method reported in literature ${ }^{4}$. All other chemicals used were of laboratory grade. 


\section{Synthesis of 5-[4-N,N-diethylamino sulfonyl phenylazo)-8-quinolinol}

Diazotization of $N, N$-diethylamino sulfonyl aniline was carried out by usual method ${ }^{5}$. The diazo salt solution was then coupled with 8-hydroxy quinoline. 8-HQ (0.01 mole) was dissolved in required amount of aqueous alkali and the solution was then cooled to $0-5{ }^{\circ} \mathrm{C}$. To this well stirred solution, the diazonium salt of $\mathrm{N}-\mathrm{N}$-diethylamino sulfonyl aniline was added slowly, so that temperature did not rise above $5{ }^{\circ} \mathrm{C}$. While maintaining $\mathrm{pH} 4.5-5.5$ by the action of sodium acetate solution $(10 \%$ $\mathrm{w} / \mathrm{v}$ ) the mixture was then stirred for $1 \mathrm{~h}$ at $0-5{ }^{\circ} \mathrm{C}$. The resulting solid dye material was filtered off and washed with boiling water and then air dried. It was red amorphous powder. It is insoluble in common organic solvent but soluble only in formic acid and DMSO. It did not melt up to $230{ }^{\circ} \mathrm{C}$

\section{Synthesis of metal chelate of DSAQ}

The metal chelates of DSAQ were prepared in two steps. All the metal chelates were prepared in an identical procedure. The details are given as follows.

\section{Preparation of DSAQ solution}

DSAQ $(0.05 \mathrm{~mol})$ was taken in $500 \mathrm{~mL}$ beaker. Formic acid was added up to slurry formation. To this slurry water was added till the complete dissolution of DSAQ. It was diluted to $100 \mathrm{~mL}$.

\section{Synthesis of DSAQ-metal Chelates}

In a solution of metal acetate $(0.005 \mathrm{~mol})$ in acetone: water $(50: 50 \mathrm{v} / \mathrm{v})$ mixture $(40 \mathrm{~mL}), 20$ $\mathrm{mL}$ of above mentioned DSAQ solution (i.e containing 0.01 M DSAQ) was added with vigorous stirring at room temperature. The appropriate $\mathrm{pH}$ was adjusted by the addition of sodium acetate for complete precipitation of metal chelate. The precipitates were digested on a boiling water bath. The precipitates of chelate were filtered off, washed by water and air dried.

The elemental contents $\mathrm{C}, \mathrm{H}, \mathrm{N}$ were determined by thermo analyzer. The metals were determined volumetrically by Vogel's method. The sulfur content was determined by carius method ${ }^{6}$. To a $100 \mathrm{mg}$ sample, each $1 \mathrm{~mL}$ of $\mathrm{HCl}(\mathrm{AR}), \mathrm{H}_{2} \mathrm{SO}_{4}$ and $\mathrm{HClO}_{4}$ were added and then $1 \mathrm{~g}$ of $\mathrm{NaClO}_{4}$ was added. The mixture was evaporated to dryness and the resulting salt was dissolved in double distilled water and diluted to the mark. From this solution the metal content was determined by titration with standard EDTA solution. Infrared spectra of the synthesized compound were recorded on Nicolet 760 FT-IR spectrometers. NMR spectrum of DSAQ was recorded on $400 \mathrm{MH}_{\mathrm{Z}}$ NMR spectrometers. Magnetic susceptibility measurement of the synthesized complexes was carried out on Gouy balance at room temperature. The electronic spectra of complexes in solid were recorded at room temperature. $\mathrm{MgO}$ was used as reference. Antifungal activity of all the samples was monitored against various fungi, following the method reported in literature ${ }^{7}$.

\section{Results and Discussion}

The synthesis of 5-[4- $N, N$-diethylamino sulfonyl phenyl azo)-8-quinolinol (DSAQ) was performed by a simple azo dye formation process ${ }^{5}$. The resultant DSAQ ligand was an amorphous dark red powder. The $\mathrm{C}, \mathrm{H}, \mathrm{N}$ content of DSAQ is presented in Table 1. The data are consistent with the structure predicted (Scheme 1). The IR spectrum of DSAQ comprises the important bands due to 8quninoliniol. The bands were observed at 1630,1575,1500,1470 and $750 \mathrm{~cm}^{-1}$.

The broad band due to $-\mathrm{OH}$ group appeared at $3800-2700 \mathrm{~cm}^{-1}$. In this band the infelctions are observed at 2890, 2950 and $1350 \mathrm{~cm}^{-1}$. These might be attributed due to $\mathrm{CH}_{3}$. The NMR spectrum of DSAQ in DMSO indicates that the singlet at $2.4 \mathrm{ppm}$ due to $\mathrm{CH}_{3}$, while the singlet at $3.8 \delta \mathrm{ppm}$ due to -OH group. The aromatic portions are appeared in the form of multiplet between 6.5 to $7.2 \delta \mathrm{ppm}$. The number of azo and hydroxyl groups of the ligands are found to be one ${ }^{7}$.Thus the structure of DSAQ is confirmed as shown in Scheme 1. 
Table 1. Analytical data of DSAQ ligand and its metal chelates.

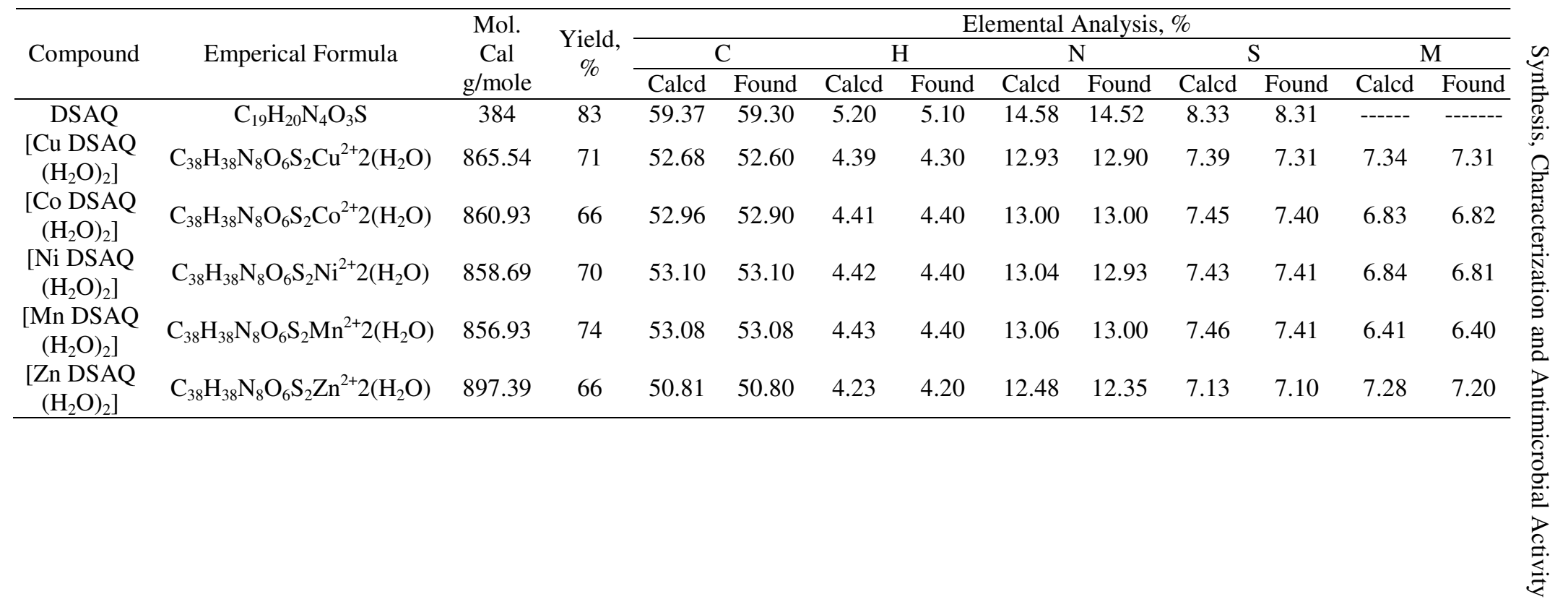


<smiles>CCN(CC)S(=O)(=O)c1ccc(N)cc1</smiles>

4-(N,N-diethylamino sulfonyl) aniline

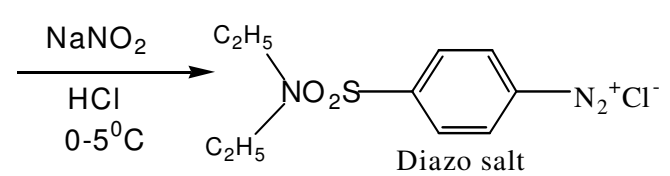

8-HQ<smiles>CCN(CC)OSc1ccc(N=Nc2ccc(O)c3ncccc23)cc1</smiles>

Metal Salt<smiles></smiles>

DSAQ-metal complex

\section{Scheme 1}

$$
\mathrm{M}: \mathrm{Cu}^{2+}, \mathrm{Ni}^{2+}, \mathrm{Co}^{2+}, \mathrm{Mn}^{2+}, \mathrm{Zn}^{2+}
$$

The metal and $\mathrm{C}, \mathrm{H}, \mathrm{N}$ contents of metal chelates of DSAQ are also consistent with the predicted structure. The results show that the metal:ligand (M:L) ratio for all divalent chelate is 1:2.

The infrared spectra of all the chelates are identical and suggest the formation of all the metalocyclic compound by the absence of band characteristic of free - $\mathrm{OH}$ group of parent DSAQ. The other bands are almost at their respectable positions as appeared in the spectrum of parent-DSAQ ligand. However, the band due to (M-O) band could not be detected as it may appear below the range of instrument used. The important IR spectrum data are shown in Table 2. Magnetic moments of metal chelates are given in Table 2. The diffuse electronic spectrum of $\mathrm{Cu}^{2+}$ chelate shows two broad bands around 15000 and $23000 \mathrm{~cm}^{-1}$. 
The first band may be due to ${ }^{2} \mathrm{~B}_{1 \mathrm{~g}} \rightarrow{ }^{2} \mathrm{~A}_{1 \mathrm{~g}}$ transition while the second band may be due to charge transfer. The first band shows structures suggesting a distorted octahedral structure for the $\mathrm{Cu}^{2+}$ metal chelate ${ }^{9-10}$. The higher value of the magnetic moment of the $\mathrm{Cu}^{2+}$ chelate supports the same. The $\mathrm{Co}^{2+}$ metal chalet gives rise to two absorption bands at 22719 and $15254 \mathrm{~cm}^{-1}$ which can be assigned ${ }^{4} \mathrm{~T}_{1 \mathrm{~g}}(\mathrm{~F}) \rightarrow{ }^{4} \mathrm{~T}_{2 \mathrm{~g}}(\mathrm{~F}),{ }^{4} \mathrm{~T}_{1 \mathrm{~g}}(\mathrm{~F}) \rightarrow{ }^{4} \mathrm{~T}_{2 \mathrm{~g}}$, transition, respectively ${ }^{11,12}$. These absorption bands and the $\mu_{\text {eff }}$ value indicate an octahedral configuration of the $\mathrm{Co}^{2+}$ metal chelate ${ }^{11}$. The spectrum of $\mathrm{Mn}^{2+}$ polymeric chelate comprised two bands at $18340 \mathrm{~cm}^{-1}$ and $23854 \mathrm{~cm}^{-1}$. The latter does not have a very long tail. These bands may be assigned to ${ }^{6} \mathrm{~A}_{1 \mathrm{~g}} \rightarrow{ }^{4} \mathrm{~T}_{2 \mathrm{~g}}(4 \mathrm{G})$, and ${ }^{6} \mathrm{~A}_{1 \mathrm{~g}} \rightarrow{ }^{4} \mathrm{~A}_{2 \mathrm{~g}}\left({ }^{4} \mathrm{E}_{\mathrm{g}}\right)$, transitions, respectively. The high intensity of the bands suggests that they may have some charge transfer character. The magnetic moment is found to be lower than normal range. In the absence of low temperature measurements of magnetic moment it is difficult to attach any significance to this. As the spectrum of the metal chelate of $\mathrm{Ni}^{2+}$ show two distinct bands a $22570 \mathrm{~cm}^{-1}$ and $15360 \mathrm{~cm}^{-1}$ are assigned as ${ }^{3} \mathrm{~A}_{1} \mathrm{~g}(\mathrm{~F}) \rightarrow{ }^{3} \mathrm{~T} 1_{\mathrm{g}}(\mathrm{P})$, and ${ }^{3} \mathrm{~A}_{1 \mathrm{~g}} \rightarrow{ }^{3} \mathrm{~T}_{1 \mathrm{~g}}(\mathrm{~F})$ transition respectively suggested the octahedral environment for $\mathrm{Ni}^{2+}$ ion. The observed $\mu_{\text {eff }}$ values in the range 3.01-3.2 B.M are consistent with the above moiety ${ }^{8,9}$.

Table 2. Spectral features and magnetic moment of DSAQ metal chelates.

\begin{tabular}{|c|c|c|c|c|c|}
\hline $\begin{array}{c}\text { Metal } \\
\text { Chelates }\end{array}$ & $\begin{array}{l}\mu_{\text {eff }} \\
\mathrm{BM}\end{array}$ & $\begin{array}{l}\text { Electronic spectral } \\
\text { data, } \mathrm{cm}^{-1}\end{array}$ & Transition & \multicolumn{2}{|c|}{$\begin{array}{l}\text { IR spectral features } \\
\text { common for all, } \mathrm{cm}^{-1}\end{array}$} \\
\hline DSAQ-Cu ${ }^{2+}$ & 2.10 & $\begin{array}{l}23245 \\
15869\end{array}$ & $\begin{array}{l}\text { Charge transfer } \\
{ }^{2} \mathrm{~B}_{1 \mathrm{~g}} \rightarrow{ }^{2} \mathrm{~A}_{1 \mathrm{~g}}\end{array}$ & $\begin{array}{l}1640 \\
1570 \\
1503 \\
1460\end{array}$ & $\begin{array}{l}\text { Quinoline } \\
\text { moiety }\end{array}$ \\
\hline DSAQ $-\mathrm{Ni}^{2+}$ & 3.29 & $\begin{array}{l}22570 \\
15360\end{array}$ & $\begin{array}{l}{ }^{3} \mathrm{~A}_{1 \mathrm{~g}} \rightarrow{ }^{3} \mathrm{~T}_{1 \mathrm{~g}}(\mathrm{P}) \\
{ }^{3} \mathrm{~A}_{1 \mathrm{~g}} \rightarrow{ }^{3} \mathrm{~T}_{1 \mathrm{~g}}(\mathrm{~F})\end{array}$ & $\begin{array}{l}2920 \\
2852 \\
1431\end{array}$ & $\mathrm{CH}_{2}$ \\
\hline DSAQ $-\mathrm{Co}^{2+}$ & 4.65 & $\begin{array}{l}22719 \\
15252 \\
8935\end{array}$ & $\begin{array}{c}{ }^{4} \mathrm{~T}_{1 \mathrm{~g}}(\mathrm{~F}) \rightarrow{ }^{4} \mathrm{~T}_{2 \mathrm{~g}}(\mathrm{~F}) \\
{ }^{4} \mathrm{~T}_{1 \mathrm{~g}}(\mathrm{~F}) \rightarrow^{4} \mathrm{~T}_{2 \mathrm{~g}} \\
{ }^{4} \mathrm{~T}_{1 \mathrm{~g}}(\mathrm{~F}) \rightarrow{ }^{4} \mathrm{~T}_{2 \mathrm{~g}}(\mathrm{P})\end{array}$ & $\begin{array}{c}1110 \\
502\end{array}$ & $\begin{array}{c}\text { C-O-M \& } \\
\text { O-M } \\
\text { bands }\end{array}$ \\
\hline DSAQ $-\mathrm{Mn}^{2+}$ & 5.40 & $\begin{array}{l}23854 \\
18340 \\
16814\end{array}$ & $\begin{array}{c}{ }^{6} \mathrm{~A}_{1 \mathrm{~g}} \rightarrow{ }^{6} \mathrm{~A}_{2 \mathrm{~g}} \mathrm{E}_{\mathrm{g}} \\
{ }^{6} \mathrm{~A}_{1 \mathrm{~g}} \rightarrow{ }^{4} \mathrm{~T}_{2 \mathrm{~g}}(4 \mathrm{G}) \\
{ }^{6} \mathrm{~A}_{1 \mathrm{~g}} \rightarrow{ }^{4} \mathrm{~T}_{1 \mathrm{~g}}(\mathrm{PG})\end{array}$ & $\begin{array}{l}710- \\
750\end{array}$ & $\mathrm{Ar}-\mathrm{Cl}$ \\
\hline DSAQ $-Z^{2+}$ & Diamag. & & --------- & ------ & ------ \\
\hline
\end{tabular}

The results of the examination of antifungal activity of DSAQ ligand and its all chelates (Table 3) reveals that the ligand is moderately toxic against fungi, while all the chelates are more toxic than ligand. Among all the chelates the $\mathrm{Cu}^{2+}$ chelates is more toxic against fungi.

Table 3. Antifungal activity of DSAQ ligand and its metal chelates.

\begin{tabular}{|c|c|c|c|c|c|c|c|}
\hline \multirow{2}{*}{ Sample } & \multicolumn{7}{|c|}{ Zone of inhibition of fungus at $1000 \mathrm{ppm}, \%$} \\
\hline & $\mathrm{PE}$ & BT & $\mathrm{N}$ & $\mathrm{T}$ & $\mathrm{RN}$ & $\mathrm{AN}$ & TL \\
\hline DSAQ & 55 & 54 & 53 & 63 & 63 & 67 & 70 \\
\hline DSAQ - $\mathrm{Cu}^{2+}$ & 83 & 78 & 77 & 83 & 81 & 81 & 85 \\
\hline DSAQ - $\mathrm{Zn}^{2+}$ & 75 & 64 & 63 & 77 & 83 & 83 & 84 \\
\hline DSAQ - $\mathrm{Ni}^{2+}$ & 80 & 77 & 75 & 75 & 73 & 81 & 80 \\
\hline DSAQ - $\mathrm{Co}^{2+}$ & 65 & 75 & 75 & 73 & 78 & 79 & 85 \\
\hline DSAQ - $\mathrm{Mn}^{2+}$ & 79 & 74 & 73 & 75 & 80 & 77 & 83 \\
\hline
\end{tabular}

$P E=$ Penicillium expansum $; B T=$ Bortydepladia thiobromine $; N=$ Nigrospara $s p ; . A N=$ Asperginus niger $T=$ Trichothesium sp.; $R N=$ Rhizopus nigricans; $T L=$ Trichoderma lignorum 


\section{References}

1. Vogel's A I, A Textbook of Quantitative Chemical Analysis, Revised by Besselt J, Denny R C, Jeffery J H and Mendham J, ELBS Ed., 1996, 5.

2. Ivanor V M and Metkina T F, Ah Anal Khim., 1978, 33, 2426.

3. Bruckhalter J H, Stephars V C, Searberough H C, Briniger W S and Dergton W E, J Am Chem Soc., 1954, 76, 4902.

4. $\quad$ Patel H S and Patel V K, Indian J Heterocycl Chem., 2003, 12, 253.

5. Vogel A I, Elementary Practical Organic Chemistry, Part 3, CBS Publisher \& Distributors, India, 1987.

6. Bance S, Handbook of Practical Organic Microanalysis, Ellis Horwood Limited, New York, 1980.

7. Barry A L, The Antimicrobial Susceptibility Test, Principal and Practice, Lea \& Febiger, Philadeiphia, 1976.

8. Lever A B F, Inorganic Electronic Spectroscopy, Elsevier, New York, 1968.

9. Figgis B N and Lewis J, Prog Inorg Chem., 1969, 6, 97.

10. Satpathy K C Pande A K, Mishra R and Panda I, Synth React Inorg Met Org Chem., 1991, 21. 531.

11. Caroline R L and Van Dryneveldt A J, Magnetic properties of transition metal compounds, Springer Verlag, New York, 1997.

12. Kettle S F A, Coordination Compounds Applection-Century-Crofts. New York, 1969. 


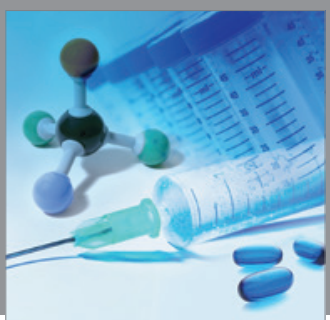

International Journal of

Medicinal Chemistry

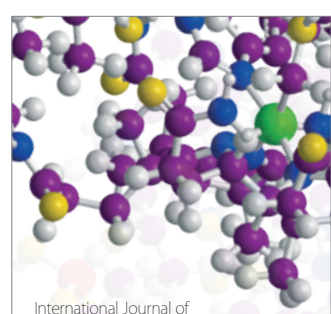

Carbohydrate Chemistry

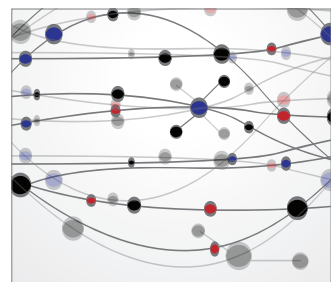

The Scientific World Journal
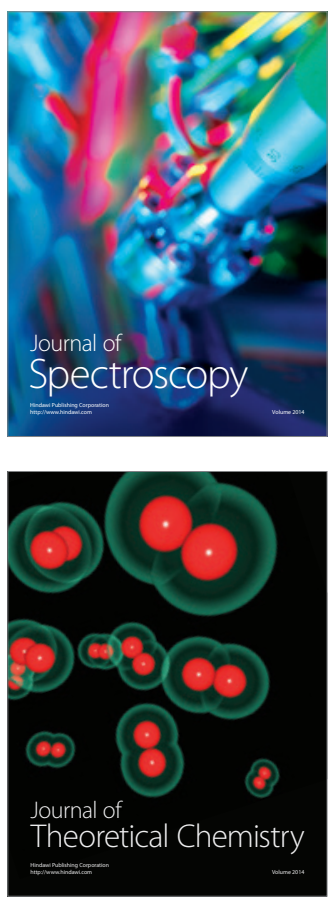
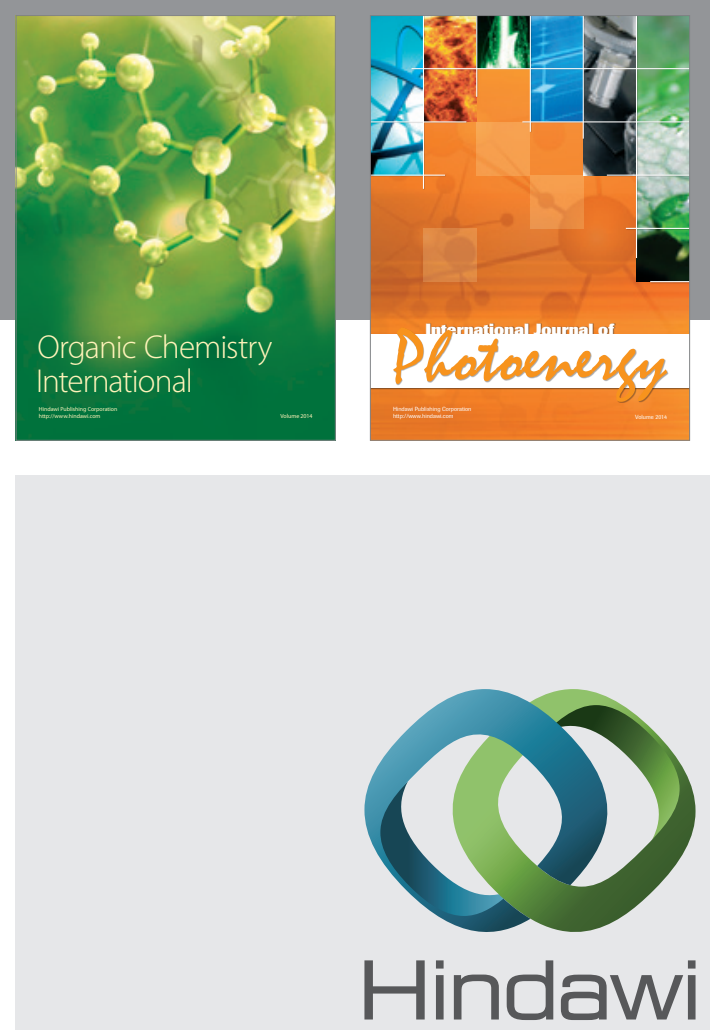

Submit your manuscripts at

http://www.hindawi.com
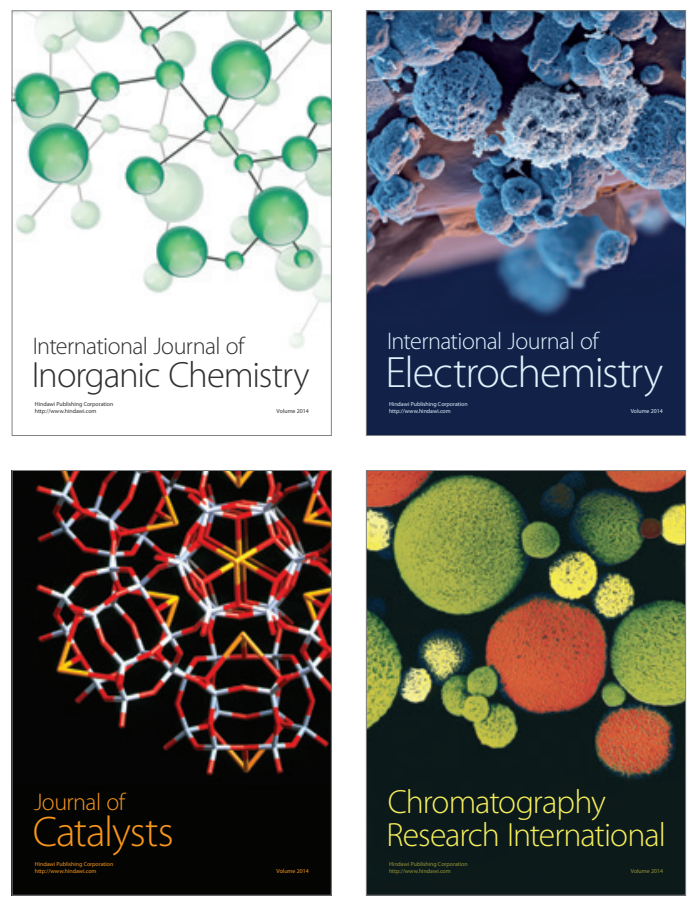
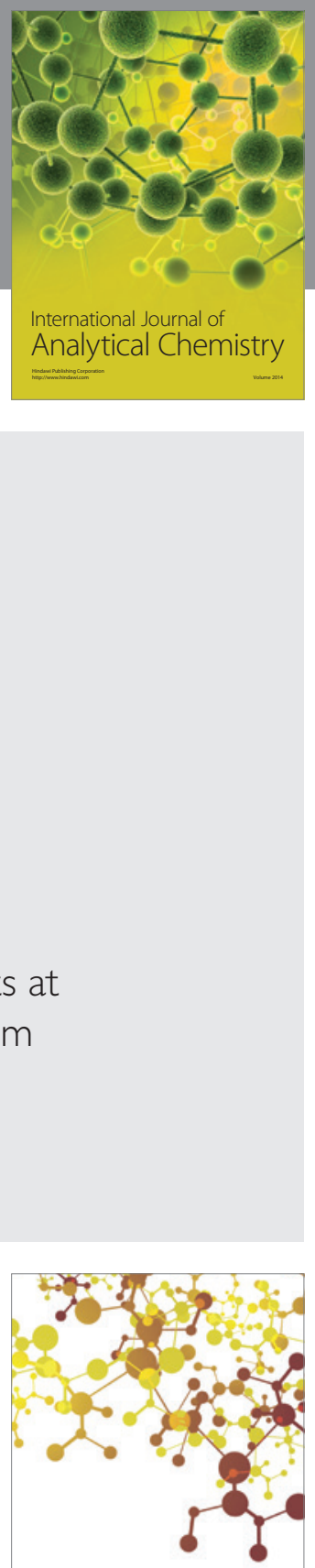

Journal of

Applied Chemistry
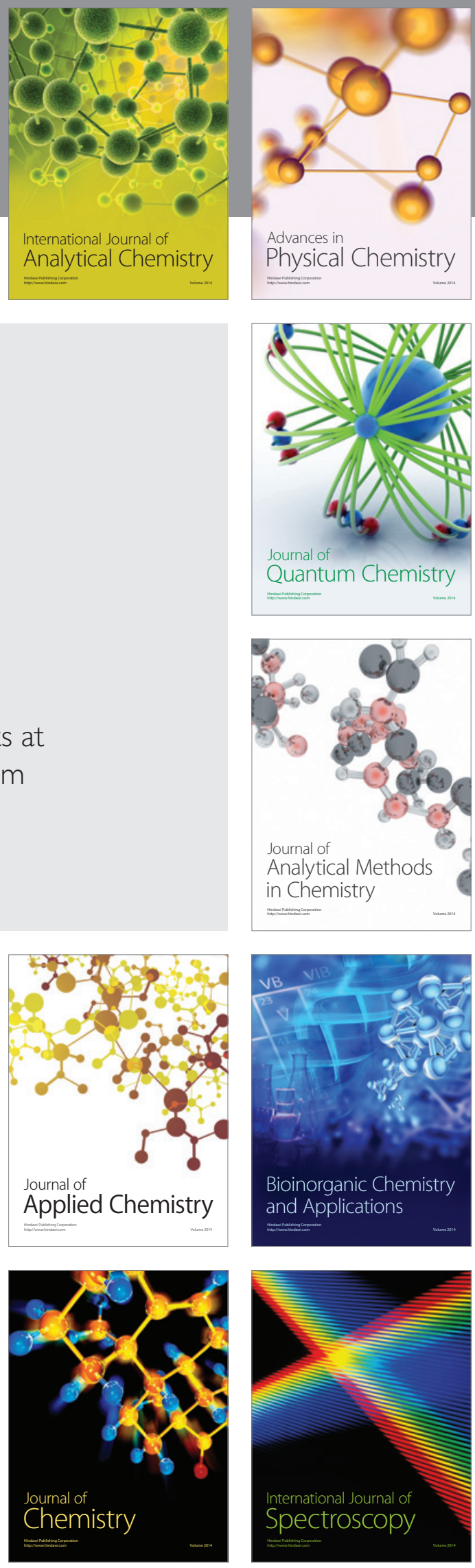